\title{
Merits of empirical and mechanistic approaches to the study of energy metabolism
}

\author{
BY K. J. MCCRACKEN \\ Food and Agricultural Chemistry Department, The Queen's University of Belfast and Department \\ of Agriculture, Northern Ireland, Newforge Lane, Belfast BT9 5PX
}

The title implies a clear separation of two approaches to the understanding of energy metabolism, which seldom, if ever, applies. Those empirical relationships which have stood the test of time were based on the concept of some uniformity of physiological function arising from an underlying and universal mechanism. Conversely the most sophisticated computer simulations of energy metabolism from cellular kinetics ultimately depend on empirical relationships which can be validated only by accurate measurements of whole-body energy expenditure.

However, there are marked differences of philosophy and of purpose between empirical and mechanistic approaches. These were succinctly described by Baldwin \& Miller (1989), and the author can do no better than to paraphrase two paragraphs of their comments.

'The term empirical is appropriate to describe models/equations wherein data obtained in input:output animal experiments were used to parameterize equations. In a strict sense the only restriction imposed on defining empirical equations is that the equations should best describe relationships among two or more variables, i.e. the equations need not imply anything about underlying/metabolic relationships. Many models based on empirical relationships have been developed and have been useful when applied carefully and with appropriate recognition of the limitation that such equations only apply within the range and conditions of the collected data used to parameterize the model.

Mechanistic models/equations, by definition are based on our understanding of underlying cause-and-effect relationships and should apply to a wide range of conditions. The use of the term mechanistic implies that our knowledge of the system is complete and, further, that sufficient biochemical, physiological and metabolic data are available to parameterize all the mechanistic equations in the model. This is rarely, if ever, the case.'

The main purpose of empirical relationships in the field of energy metabolism, as in other aspects of biological science, has been to identify and quantify the degree of uniformity of biological function within and between species. The secondary purpose has been to apply these relationships in order to determine energy requirements for different species in relation to specific physiological status, and this has been the cornerstone of development of feeding systems for animal production and of recommended dietary intakes for humans. Most notable among the empirical relationships are those relating to the allometry of growth and organ development, the surface area law and the inter-specific relationship between basal metabolism and metabolic body size. During the 1970 s the increased availability of personal computers, coupled with the vast data pools which had been accumulated during the previous 20 years, gave an impetus to the development of complex factorial models such as the Edinburgh pig model (Whittemore 
\& Fawcett, 1976) and models based on the factorial approach to the energy metabolism of cattle advocated by Blaxter (1962).

As more fully discussed by Webster (1992) these empirical models dealt with energy in terms of metabolizable energy, whereas the mechanistic models deal with substrate conversions to ATP. The last decade has seen a rapid expansion of the use of computers to develop mechanistic models, e.g. Gill et al. (1984), Pettigrew et al. (1989), Oltjen (1991), but the high point in this area must undoubtedly be the triad of papers by Baldwin, University of California and the group at Hurley (Baldwin et al. 1987a,b,c), on the development of a mechanistic model for the metabolism of the lactating cow. Whilst, inevitably, there are many empirical elements within the model indicating the present inadequacies of biochemical, physiological and metabolic data, this is without doubt the forerunner of models which will be more purely mechanistic as further areas of uncertainty are removed. In the immediate future, however, it seems reasonable to agree with Baldwin \& Miller (1989) that the main value of mechanistic models is to 'evaluate current understanding of a system or sub-system for adequacy; and when current understanding is inadequate, identify critical experiments; or, to identify, characterize and validate mechanistic equations for insertion into empirical models', whereas practical applications will continue to depend on the careful use of empirical models expanded, where appropriate, by mechanistic equations.

This statement is readily supported by a consideration of the problems of accurately predicting the availability of substrate from known dietary intakes, even in nonruminants, and to a much greater extent in ruminants (Baldwin et al. 1987c; Dewhurst \& Webster, 1989), and by examination of the multitude of assumptions, empirical relationships and arbitrary corrections used in the current family of mechanistic models. For example, Gill et al. (1984) used the empirical relationship of Black \& Griffiths (1975) to estimate the maximum rate of protein synthesis and the empirical equation of Graham et al. (1976) to calculate maintenance energy requirements. Similarly, Pettigrew et al. (1989) estimated values for maximum reaction rates and for affinity and inhibition constants from empirical data on such measures as body protein, fat depletion and milk yield of sows. Baldwin et al. (1987b) obtained a remarkable degree of agreement with energy balance data but did so by permitting unrealistically large pool sizes to minimize the problems of using unmodulated reaction rates. This raises a serious question as to the ultimate practicability of mechanistic models. Newsholme (1985) put the problem in perspective by defining the high level of precision involved in every metabolic control mechanism. For example, a $1 \%$ overstimulation of fat mobilization during endurance running would give rise to dangerously high levels of plasma fatty acids within $1 \mathrm{~h}$. There is no possibility of measuring reaction rates to such a degree of accuracy and we are, therefore, forced to accept arbitrary limits which result in physiologically acceptable levels of circulatory metabolites. Can we ever hope, therefore, to explain the abnormal or even to mirror the normal other than in terms of arbitrary mathematical relationships based on empirical knowledge?

The previous comments are not included to decry the potential value of mechanistic models but to support the eloquent comment of Webster (1992) that if complex mechanistic models of the supply and metabolism of energy-yielding nutrients are to be useful as distinct from merely clever, then they will always have to be calibrated against standards based on simple energy conversions'.

Having established this point we do well to ask how good are the standards which have 
been achieved in quantifying energy exchange and how sound are the empirical relationships from which so much of our current energy requirements are calculated. Much of the rest of the present paper will attempt, however inadequately, to assess some of these in terms of four criteria: (1) accuracy and universality, (2) biological relevance, (3) limitations and misuse, (4) extent to which mechanistic models can explain or improve them.

One of the empirical relationships which has undoubtedly stood the test of time is the surface area law and the concept of the inter-specific relation of body size and metabolic rate. Its origins are attributed by Kleiber (1961) to Sarrus \& Rameaux who wrote a thesis which Thillaye read to the Royal Academy of France during its meeting of 23 July 1839. The authors apparently began with the concept that there is an underlying mechanism for the control of body temperature by regulating heat production in relation to surface area and that this is achieved by modulating the frequency of heart beat and pulse volume. The universality of application of the surface area law to fasting adults, at rest within the thermoneutral zone has been well established. However, the problems of measuring surface area limited the value of the concept and the simpler approach of using a power function of body-weight (W) as the basis of metabolic body size (Krogh, 1916; Brody et al. 1928; Kleiber, 1932) has become generally accepted in relation to animal nutrition, the $\mathrm{W}^{0.75}$ power advocated by Kleiber (1932) being widely used. The physiological basis for this phenomenon has been and remains the source of much controversy. Despite the massive increase in our knowledge of the biochemical and physiological mechanisms involved in energy metabolism it is difficult to improve on the inspired thesis of Sarrus \& Rameaux in terms of explaining either how or why this relationship should hold so well for a range of homeotherms from mice to elephants. The limitation to the relationship is of course in the conditions under which it holds, namely those relating to the measurement of basal metabolism and to inter-specific comparisons. Unfortunately this aspect is often ignored and the use of metabolic body size $\left(\mathrm{W}^{0.75}\right)$ has become widely used to make intra-specific comparisons of heat production on animals of different weight (usually not because of strain differences but differences in stage of maturity) at different levels of feeding and activity and even at different environmental temperatures, despite the considerable literature going back at least 50 years which has emphasized this limitation. For example, Breirem (1936) demonstrated that for the fasting pig between 20 and $120 \mathrm{~kg}$ the power function $\mathrm{W}^{0.57}$ yields an almost constant term whereas $\mathrm{W}^{0.75}$ or $\mathrm{W}^{1 \cdot 00}$ give values which decline significantly with increasing weight. Similarly, Kleiber et al. (1956) showed that, using $\mathrm{W}^{0.75}$, the 'constant' increased in the post-weaning rat and then gradually declined by almost $40 \%$ to adult values.

A further concept which has been widely used in animal metabolism is that of 'maintenance'. The classical approach to the determination of maintenance is to feed at two levels either above or below but with one level close to 'maintenance' and to extrapolate to zero energy balance. This empirically derived value has generally been expressed per unit metabolic body size $\left(\mathrm{W}^{0.75}\right)$ and has been of considerable value as a basis for factorial calculations of energy requirements for growth, lactation and gestation. In relation to the earlier discussion about the problem of using $\mathrm{W}^{0.75}$ as a basis for comparisons in growing animals some workers have supported the use of lean body mass as a more appropriate basis for comparing maintenance (Pullar \& Webster, 1977), and Whittemore (1983) suggested that the relationship $\mathrm{ME}_{\mathrm{m}}=1.85 P_{b}^{0.78}$ (where $\mathrm{ME}_{\mathrm{m}}$ is metabolizable energy requirement for maintenance and $P_{b}$ is body protein) is more 
appropriate for estimating maintenance requirements of the growing pig than estimates based on $\mathrm{W}^{0.75}$ or $\mathrm{W}^{0.63}$ (Agricultural Research Council, 1981).

Despite the undoubted value of the use of the maintenance concept, the term only has real biological meaning in an adult human or animal in a non-productive state under defined conditions of temperature and activity consuming sufficient energy to maintain energy equilibrium. Furthermore, it is arguable that its use, particularly for growing animals, has inhibited consideration of the lability of body metabolism in response to changes in energy intake. This is an important topic both in human and animal energy metabolism and there is not sufficient space here to do it justice. However, a few examples can be cited to give perspective to the discussion. The most extreme adaptation found in the literature is that in the undernourished pigs of McCance \& Mount (1961). Whereas the maintenance requirement of a young pig is about $600 \mathrm{~kJ} / \mathrm{kg} \mathrm{W}^{0.75}$ and that of an adult about $400 \mathrm{~kJ} / \mathrm{kg} \mathrm{W}^{0.75}$, it can be calculated that the energy intake of their pigs was about $250 \mathrm{~kJ} / \mathrm{kg} \mathrm{W}^{0.75}$. Since body fat reserves had been totally depleted it must be assumed that these animals had reduced their energy expenditure by at least $50 \%$ below what would be regarded as normal. During a much shorter period of restriction piglets given inadequate energy or protein showed reductions in 'maintenance requirement' of approximately 10\% compared with normal litter-mates (McCracken \& McAllister, 1984) and Gray \& McCracken (1979) demonstrated a $12 \%$ reduction in heat production of pigs given a maintenance intake $(\mathrm{M})$ immediately after a period on $2 \mathrm{M} v .3 \mathrm{M}$ (i.e. a reduction in intake). Black et al. (1986) developed the Whittemore (1983) approach for growing pigs by incorporating a term to modify maintenance requirements in relation to growth rate and the factor in their equation fits well with the observations of Gray \& McCracken (1979). Furthermore, it provides estimates of maintenance requirement for pigs of high genetic potential (McCracken \& Rao, 1989; Rao \& McCracken, 1991) which agree with the observed values, whereas the equations of Agricultural Research Council (1981) and Whittemore (1983) underestimate by 27 and $14 \%$ respectively. The failure of the Agricultural Research Council (1981) equation to predict requirements for these pigs is probably an excellent illustration of the golden rule not to use empirical relationships outside the range of data on which they were based, since the ceiling for protein deposition potential in the pigs of McCracken \& Rao (1989) was approximately $50 \%$ higher than those in pigs used in studies on which the Agricultural Research Council (1981) relationship was determined.

On the other hand attempts to show changes in maintenance requirement of older growing animals or adults in response to over- or underfeeding have tended to give negative results. For example, in a major review, van Es (1972) concluded that 'no reliable indication was found that the maintenance requirement changes with the level of production. It may, however, easily be changed by increased levels of (muscular) activity'. In this respect, the results of McCracken \& McNiven (1983) with adult rats, which had more than doubled their initial weight due to overfeeding, are an interesting demonstration of the value and limitations of empirical approaches. These animals increased fasting metabolic rate exactly in proportion to metabolic body-weight $\left(\mathrm{W}^{0 \cdot 75}\right)$ and to a much greater extent than the increase in lean body mass. In practical terms, therefore, they appear to strongly support the view of van Es (1972) that the maintenance requirement of adult animals is not significantly affected by energy intakes above maintenance, and at the same time refute the view of Pullar \& Webster (1977) that maintenance requirements are better equated to lean body mass than to metabolic body 
size. It is, nevertheless, dangerous to attempt to give any physiological explanation. It is possible that this is nothing more than a mathematical accident in that increased turnover in certain tissues was diluted by the large increase in metabolically less active adipose tissue. In contrast, studies on the basal metabolic rate of lean and obese humans normally show a good correlation with lean body mass rather than with total weight or metabolic body size $\left(\mathrm{W}^{0.75}\right)$. It would be interesting to see to what extent mechanistic modelling could provide a rationale for these observations.

Kielanowski (1965) gave impetus to the application of multiple-regression techniques to estimate maintenance and the partial efficiency of energy utilization of protein and fat $\left(k_{p}\right.$ and $k_{f}$ ). This has been the basis for the development of factorial approaches to energy requirements, e.g. for growing pigs (Agricultural Research Council, 1981).

This empirical approach is open to much valid criticism. The relationship is usually expressed as:

$$
\mathrm{MEI}=A W^{b}+1 / k_{p} P_{e}+1 / k_{f} F_{e}+c,
$$

where MEI is the metabolizable energy intake, $A W^{b}+c$ represents maintenance, and $P_{e}$ and $F_{e}$ are the amounts of energy deposited as protein and fat respectively. Mathematically speaking MEI is the dependent variable and the other terms are the independent variables. In practice it is almost the reverse, i.e. MEI are imposed experimentally and protein and fat deposition are the result of genetic potential, stage of maturity and intakes of protein and energy. Despite this criticism the careful use of the multiple-regression technique has been the backbone for the development of empirical models of energy metabolism for growth and lactation. As Webster (1992) has pointed out, the agreement between the estimates of the cost of fat deposition in non-ruminants from multiple regression and stoichiometric calculations of fat synthesis (Armstrong, 1969 ) is remarkably good. On the other hand the consistently low values for $k_{p}$ in the rat and pig compared with the stoichiometric calculations have been the cause of much controversy. The fact that protein synthesis and degradation are six to eight times greater than protein deposition may provide a partial explanation but, so far as the author is aware, no one has managed to provide a complete and convincing explanation for the low observed $k_{p}$ values.

One further aspect of the multiple-regression approach when applied to calorimetric data on growing animals is the long recognized, but frequently ignored, problem of overestimation of nitrogen retention by the balance method. This is probably a less serious problem in human studies where better control can be exercised over urine collection. The problem is greatest with classical separation techniques and is exacerbated by increases in dietary protein content. With pigs, $\mathrm{N}$ balance usually overestimates retention relative to slaughter data by 10-20\% (McCracken et al. 1980; Just et al. 1982) and many studies in the literature on animals from rats to cattle are subject to much larger errors. It is almost certainly the case that there is a small systematic underestimation of $\mathrm{N}$ retention by the slaughter method, but it is equally certain that the more serious errors lie in the balance data due both to overestimation of intake and underestimation of excretion. This indicates that many estimates of $k_{p}$ by balancecalorimetry may be too high.

However, problems of error due to methodological difficulties are not just found with $\mathrm{N}$ balance. As Webster (1992) has pointed out there are also difficulties in obtaining agreement between energy retention calculated from respiratory exchange and from 
slaughter studies. In many cases this is apparently not due to errors in measurement but in different responses (in terms of alertness, feeding behaviour, activity, etc.) in confined/isolated environments. In this respect we have been concerned for the last few years about what appears to be a large error in the empirical relationship established by Agricultural Research Council (1980), between metabolizability of diets for cattle and the efficiency of energy utilization for growth $\left(k_{g}\right)$. A major slaughter study of beef cattle (McCracken et al. 1991) has confirmed a large discrepancy between the $k_{g}(0 \cdot 52)$ predicted by Agricultural Research Council (1980) and the determined value $(0 \cdot 39)$, which is in line with predictions from Garrett (1979). Similar problems occur in studies on pigs and rats. For example, McCracken \& Rao (1989) using high-genetic-potential boars, determined values of heat production by slaughter and calorimetry which were respectively $19 \cdot 0$ and $17.4 \mathrm{MJ} / \mathrm{d}$, and McCracken \& McAllister (1984) observed a 10\% difference between calorimetry and slaughter in the heat production of undernourished pigs which spent every third day in a closed-circuit chamber.

The previous discussion highlights serious issues in terms of providing the gold standard of measurement and interpretation which will be necessary if we are to improve quantitatively in our prediction of energy requirements. Unfortunately there is a further hazard in the literature. This hazard is flawed science. Due to the desire on the part of journal editors for concise papers and the presentation of statistically analysed summaries, the hazard is much greater today than 50 years ago when considerable amounts of raw data were presented. Occasionally enough data are available for the observant reader to identify the problem and two such examples are worthy of comment.

The first, Rothwell \& Stock (1979) contains at least three quantitative errors of considerable significance. First, the metabolizable energy content of the control diet was assumed to be $10.75 \mathrm{MJ} / \mathrm{kg}$ whereas subsequent measurement showed the true value to be $12.2 \mathrm{MJ} / \mathrm{kg}$. Thus, the energy intake of the control group was underestimated by $12 \%$ and heat production by $16 \%$. The energy gain of the cafeteria rats shown in their table is $20 \%$ less than would be calculated from the given weight of fat gain and the stated gross efficiency of the controls $(0 \cdot 36)$ is $30 \%$ greater than the value which can be calculated from MEI and e lergy retention. The other is a paper by Thorbek et al. (1982) which is notable in three iespects. First, it sets out to be a definitive study of energy and protein metabolism of the growing rat. Second, it is subject, to a calamitous extent, to the problems of $\mathrm{N}$ balance and energy retention measurement discussed previously and third and importantly it is a good illustration of how the intelligent use of simple but sound empirical relationships would have prevented the publication of data which only add confusion to the literature. Within the paper the rates of live-weight gain during each period of study can be calculated. Hence, it is possible using sensible empirical values for the crude protein $(\mathrm{N} \times 6.25)$ and energy content of the body gain to make good estimates of the protein and energy retention. However, the values reported for $\mathrm{N}$ balance and energy retention are all at least $100 \%$ greater than those compatible with the rates of gain.

Finally, I wish to consider what I believe will prove to be the greatest challenge to all involved in modelling energy metabolism both in humans and animals, namely the prediction of nutrient (energy) intake. Oldham \& Emmans (1989) have made a strong case for the prediction of responses rather than of requirements, and mechanistic models are more easily operated in this mode. Empirical models, on the other hand, can be applied in either direction. However, at present both forms of nutrient-response model 
tend to start with a known nutrient intake, though, for example, the Edinburgh pig model provides a wide range of options including an empirical estimate of $a d l i b$. feed (energy) intake. Various empirical equations have been derived for non-ruminants (Agricultural Research Council, 1981; Fisher \& Boorman, 1986) and for ruminants (Agricultural Research Council, 1980; Rook et al. 1990) but all these are subject to the problem of (as yet) unexplained animal variability. For example, McCracken \& Stockdale (1989) observed a range of mean daily intake from 1.79 to $3.13 \mathrm{~kg}$ in a highly selected pig population fed on the same diet under uniform conditions of management and environment. Similarly, the problem of wide variations in energy intake of individual humans has been recognized for a long time (Widdowson, 1962).

The optimist will suggest that increased understanding of the interactions of physiological, psychological and environmental factors will ultimately permit the prediction of intake at an individual or group level. The realist will point to the parable of the narcissus and the slob (Webster, 1992) and to Newsholme (1985) and suggest that the human or animal body operates at levels of precision which are beyond the ingenuity of man to emulate or understand. In the words of the psalmist 'we are fearfully and wonderfully made'.

Notwithstanding this (perhaps pessimistic) comment we have not yet reached the frontiers of understanding. I suggest that some of the challenges which face those dedicated to the mechanistic approach include: reduce the level of uncertainty in reaction rates, improve understanding of hormone interactions and sensitivity of receptor sites, improve methods of predicting genetic potential for lean gain in growing animals, improve understanding of the energetics of protein metabolism, accurately predict intakes of (absorbed) nutrients and energy. The challenge to all of us is to ensure that whatever experiments we conduct are designed to tackle real questions and conducted to provide accurate and interpretable results. However, extending the statement of Kleiber (1961), to matters beyond the scope of the surface area law, we may also have to accept that "the search for the "true" relation implies mystics with which we cannot cope in animal energetics'.

\section{REFERENCES}

Agricultural Research Council (1980). Nutrient Requirements of Ruminant Livestock: Technical Review by an $A R C$ Working Party. Farnham Royal: Commonwealth Agricultural Bureaux.

Agricultural Research Council (1981). The Nutrient Requirements of Pigs. Farnham Royal: Commonwealth Agricultural Bureaux.

Armstrong, D. G. (1969). Cell biogenetics and energy metabolism. In Handbuch der Tierernahrung, vol. 1, pp. 385-414 [W. Lenkeit, K. Breirem and E. Crasemann, editors]. Hamburg and Berlin: Verlag Paul Parey.

Baldwin, R. L., France, J., Beever, D. E., Gill, M. \& Thornley, J. H. M. (1987a). Metabolism of the lactating cow. 3. Properties of mechanistic models suitable for evaluation of energetic relationships and factors involved in the partition of nutrients. Journal of Dairy Research 54, 133-145.

Baldwin, R. L., France, J. \& Gill, M. (1987b). Metabolism of the lactating cow. 1. Animal elements of a mechanistic model. Journal of Dairy Research 54, 77-105.

Baldwin, R. L. \& Miller, P. S. (1989). Modelling energy metabolism. Proceedings 11th Symposium on Energy Metabolism. European Association of Animal Production, Publication no. 43, pp. 239-242. Wageningen, Netherlands: Pudoc Press.

Baldwin, R. L., Thornley, J. H. M. \& Beever, D. E. (1987c). Metabolism of the lactating cow. 2. Digestive elements of a mechanistic model. Journal of Dairy Research 54, 107-131.

Black, J. L., Campbell, R. G., Williams, J. H., James, K. J. \& Davies, G. T. (1986). Simulation of energy and amino-acid utilization in the pig. Research and Development in Agriculture 3, 121-145.

Black, T. L. \& Griffiths, D. A. (1975). Effects of live weight and energy intake on nitrogen balance and total N requirement of lambs. British Journal of Nutrition 33, 399-413. 
Blaxter, K. L. (1962). The Energy Metabolism of Ruminants. London: Hutchinson.

Breirem, K. (1936). Erhaltung-Stoffwechsel des wachsender schweiner. Tierernahrung 8, 463-498.

Brody, S., Comfort, J. E. \& Matthews, J. S. (1928). Growth and development. Further investigations on surface area with special reference to its significance in energy metabolism. Missouri Research Bulletin no. 115.

Dewhurst, R. J. \& Webster, A. J. F. (1989). Development of a practical, deterministic model for the prediction of true metabolisable energy in frozen and compound feeds. Proceedings 11th Symposium on Energy Metabolism. European Association of Animal Production, Publication no. 43, pp. 223-226. Wageningen, Netherlands: Pudoc Press.

Fisher, C. \& Boorman, K. N. (1986). Nutrient Requirements of Poultry and Nutritional Research. Poultry Science Symposium no. 19. London: Butterworth.

Garrett, W. N. (1979). Energy utilization by growing cattle as determined in 72 comparative slaughter experiments. Proceedings 8th Symposium on Energy Metabolism. European Association of Animal Production, Publication no. 26, pp. 3-7. London: Butterworths.

Gill, M., Thornley, J. H. M., Black, J. L., Oldham, J. D. \& Beever, D. E. (1984). Simulation of metabolism of absorbed energy-yielding nutrients in young sheep. British Journal of Nutrition 52, 621-649.

Graham, N. McC., Black, J. L., Faichney, G. J. \& Arnold, G. W. (1976). Simulation of growth and production in sheep - model 1. A complete program to estimate energy and nitrogen utilisation, body composition and empty liveweight change, day by day for sheep of any age. Agricultural Systems 1, 113-138.

Gray, R. \& McCracken, K. J. (1979). Plane of nutrition and the maintenance requirement. Proceedings 8th Symposium on Energy Metabolism. European Association of Animal Production, Publication no. 26, pp. 163-167. London: Butterworths.

Just, A., Jorgensen, H. \& Fernandez, J. (1982). Nitrogen balance studies and nitrogen retention. In Digestive Physiology in the Pig. Institut National de la Recherche Agronomique, Publication no. 12, pp. 111-122. [J. P. Le Place, T. Corring and A. Rérat, editors].

Kielanowski, J. (1965). Estimates of the energy cost of protein deposition in growing animals. In Proceedings 3rd Symposium on Energy Metabolism. European Association of Animal Production, Publication no. 11, pp. 13-16 [K. L. Blaxter, editor]. London: Academic Press.

Kleiber, M. (1932). Body size and metabolism. Hilgarda 6, 315-353.

Kleiber, M. (1961). The Fire of Life. New York and London: John Wiley \& Sons.

Kleiber, M., Smith, A. H. \& Chernikoff, T. N. (1956). Metabolic rate of female rats as a function of age and body size. American Journal of Physiology 186, 9-12.

Krogh, A. (1916). The Respiratory Exchange of Animals and Man. Monograph in Biochemistry. London: Longmans Green \& Co.

McCance, R. A. \& Mount, L. E. (1960). Severe undernutrition in growing and adult animals. 5. Metabolic rate and body temperature in the pig. British Journal of Nutrition 14, 509-518.

McCracken, K. J., Eddie, S. M. \& Stevenson, W. G. (1980). Energy and protein nutrition of early-weaned pigs. 2. Effect of energy intake and energy:protein on energy utilization and body composition of pigs slaughtered at 32 d. British Journal of Nutrition 43, 305-319.

McCracken, K. J. \& McAllister, A. (1984). Energy metabolism and body composition of young pigs given low-protein diets. British Journal of Nutrition 51, 225-234.

McCracken, K. J. \& McNiven, M. A. (1983). Effects of overfeeding by gastric intubation on body composition of adult female rats and on heat production during feeding and fasting. British Journal of Nutrition 49, 193-202.

McCracken, K. J., Moore, C. A., Unsworth, E. F., Gordon, F. J., Steen, R. W. J. \& Kilpatrick, D. J. (1991). Plane of nutrition effects on body composition and energy metabolism of finishing Friesian cattle given complete diets. Proceedings 12th Symposium on Energy Metabolism. European Association of Animal Production, Publication no. 58, pp. 186-189. Zürich, Switzerland: Eth-Zürich.

McCracken, K. J. \& Rao, D. S. (1989). Protein:energy interactions in boars of high lean deposition potential. Proceedings 11th Symposium on Energy Metabolism. European Association of Animal Production, Publication no. 43, pp. 13-16. Wageningen, Netherlands: Pudoc Press.

McCracken, K. J. \& Stockdale, R. J. (1989). Voluntary food intake of pigs of high genetic potential fed pellets to appetite and effects of sex and dietary protein content. The voluntary food intake of pigs. British Society of Animal Production, Occasional Publication no. 13, pp. 117-118. Haddington, UK: D. \& J. Croat.

Newsholme, E. A. (1985). Substrate cycles and energy metabolism; their biochemical, biological, physiological and pathological importance. Proceedings 10th Symposium on Energy Metabolism. European Association of Animal Production, Publication no. 32, pp. 174-186. P. Moe and H. F. Tyrrell. 
Oldham, J. D. \& Emmans, G. C. (1989). Prediction of responses to required nutrients in dairy cows. Journal of Dairy Science 72, 3212-3229.

Oltjen, J. (1991). A mechanistic model of cattle growth and composition. Proceedings 12th Symposium on Energy Metabolism. European Association of Animal Production, Publication no. 58, pp. 115-119. Zürich, Switzerland: Eth-Zürich.

Pettigrew, J. E., Gill, M., France, J. \& Close, W. H. (1989). A mathematical model of sow energy and protein metabolism. Proceedings 11th Symposium on Energy Metabolism. European Association of Animal Production, Publication no. 43, pp. 199-202. Wageningen, Netherlands: Pudoc Press.

Pullar, J. D. \& Webster, A. J. F. (1977). The energy costs of protein and fat deposition in the rat. British Journal of Nutrition 37, 355-363.

Rao, D. S. \& McCracken, K. J. (1991). Effect of energy intake on protein and energy metabolism of bears of high genetic potential for lean growth. Animal Production 52, 499-507.

Rook, A. J., Dhanoa, M. S. \& Gill, M. (1990). Prediction of the voluntary intake of grass silages by beef cattle. 3. Precision of alternative prediction models. Animal Production 50, 455-466.

Rothwell, N. J. \& Stock, M. J. (1979). A role for brown adipose tissue in diet-induced thermogenesis. Nature 281, 31-35.

Thorbek, G., Chwalibog, A., Eggum, B. O. \& Christensen, K. (1982). Studies on growth, nitrogen and energy metabolism in rats. Archiv für Tierernahrung 32, 827-840.

van Es, A. J. H. (1972). Maintenance. In Handbuch der Teirernahrung, vol. 2, pp. 1-54 [W. Lenkeit and K. Breirem, editors]. Hamburg and Berlin: Verlag Paul Parey.

Webster, A. J. F. (1991). Energy expenditure: studies with animals. In The Contribution of Nutrition to Human and Animal Health, pp. 23-32 [E. M. Widdowson and J. C. Mathers, editors]. Cambridge: Cambridge University Press.

Whittemore, C. T. (1983). Development of recommended energy and protein allowances for growing pigs. Agricultural Systems 11, 159-186.

Whittemore, C. T. \& Fawcett, R. H. (1976). Theoretical aspects of a flexible model to simulate protein and lipid growth in pigs. Animal Production 22, 87-96.

Widdowson, E. M. (1962). Nutritional individuality. Proceedings of the Nutrition Society 21, 121-128. 